\title{
nature
}

\section{Bridging the Taiwan Strait}

The political and practical obstacles to greater scientific exchange between Taiwan and the Chinese mainland are significant. It is achievable, however, and is in the best interests of both parties.

$\mathrm{T}$ he election earlier this year of Taiwan's new president Chen Shui-bian, whose Democratic Progressive Party contains radicals advocating independence, has brought political tensions with the Chinese mainland to new heights, almost verging on war. Vitriolic attacks by the mainland on pro-independence members of Chen's administration have created an atmosphere in which attempts by well-intentioned individuals, such as Nobel prizewinner Yuan-tseh Lee, to increase scientific exchange with the mainland are being seriously hampered (see Nature Regional Insight, pages 415-426). This benefits no one.

Taiwan has a well-developed infrastructure for research at its universities and government research institutes, and at Academia Sinica, Taiwan's premier institution for basic research headed by Lee. But these institutions are facing a manpower crunch. A flood of returnee scientists from the United States in the early 1990s has been reduced to a trickle as the US economy picks up and tensions with the Chinese mainland rise. Furthermore, students in Taiwan are turning their backs on $\mathrm{PhD}$ and postdoctoral research, preferring to take up positions in Taiwan's booming electronics industry or to study business management or economics rather than science.

This offers a golden opportunity for exchange with the mainland if political differences could be put aside. The Chinese mainland has a large supply of young high-quality scientists willing to do basic research. And leaders of Taiwanese research institutions have growing respect for the quality of scientists on the mainland, who still have to work under comparatively poor conditions.

Nor need the exchange be confined to basic research. One entrepreneurial scientist at Tsinghua University in Beijing, for example, has set up a start-up company for biochips in California funded with venture capital from Taiwan and plans to manufacture the chips on the island (see page 426).

At present, there are about 50 mainland Chinese scientists on short-term visits at Academia Sinica. Lee, who maintains strong links with mainland institutions and is much respected there, actively encourages mainlanders to come to Taiwan. But the duration of their stay is limited to a maximum of one year by mainland regulations. Furthermore, the visiting scientists are not issued with passports because the mainland government considers Taiwan a renegade province. This prevents the visitors from, for example, attending conferences outside Taiwan, and severely limits the value of their stay. Allowing longer stays of at least two years would be a simple step that would benefit both parties.

But it would be naive to suggest that opening the taps on exchange alone will do much to improve scientific relations between Taiwan and the mainland. Some fundamental problems still stand in the way of joint research. Many institutions in Taiwan, such as Academia Sinica and National Tsinghua University, have adopted the names of the mainland organizations from which they claim their roots. Furthermore, the word 'National' tagged onto many research institutes and university names in Taiwan, such as National Taiwan University, is like a red rag to a bull for officials on the mainland, who are vehemently opposed to any suggestion that Taiwan is a nation. This presents very practical problems if Taiwan's researchers and their colleagues on the mainland want to publish joint research in international journals. The names in the affiliations of Taiwan's researchers are often simply unacceptable to mainland organizations and the government that funds them - and in some cases, such as that of Tsinghua University, the names are the same.

Yet, with goodwill and imagination on the part of both parties, solutions to this sort of problem can be found - as, for example, can be seen in Taiwan's participation in the current Sydney Olympics under the name of Chinese Taipei.

It is essential to improve and increase scientific exchanges, and not just because it would benefit science in both Taiwan and the Chinese mainland. Anything that helps ease the political tensions across the Taiwan Strait is good for the world as a whole.

\section{Reviews for reviews' sake}

Next month sees three new Nature review titles that make the most of the partnership between editors and authors.

ournals that aim to take an overview of research have a long and honourable history. The world's longest-running journal, the Philosophical Transactions of the Royal Society, was at its outset in 1665 arguably a review journal of sorts, aimed as it was at "giving some ACCOUNT of the present undertakings, studies, labours of the INGENIOUS in many considerable parts of the WORLD".

Nature only began to publish review articles with any frequency in the 1970s, but now Nature and all of the monthly Nature journals see them as an essential part of their content. Feedback suggests that readers welcome Nature's most recent development in this direction: the Nature Insight collections that appear about once a month.

But Nature's publishers have taken a significant step further. On 1 October, visitors to http://www.nature.com/reviews/ will find three new journals, under the banner of Nature Reviews, devoted to overviews of recent highlights in genetics, neuroscience and molecular cell biology. Information on these journals can be found elsewhere in this issue.

What should perhaps be emphasized above all is the combination of quality of authors and the depth of attention given to the review articles by their editors, in terms of topics and content, readability, addition of complementary material on the web, and in the figures and web-based animation. The journals' philosophy is fully in keeping with the tradition of Nature journals, by which much of the creativity starts - and the buck stops — with the editors themselves, while the authors deliver the clout.

With many questions being asked about the addition of value by publishers, we intend for these partnerships between editors and authors of reviews to represent outstandingly positive examples. 